Bol. Acad. peru. leng. 61.2016 (125-141)

\title{
Javier Sologuren y la literatura japonesa
}

\author{
Javier Sologuren and Japanese literature \\ Pilar Derteano Galdos \\ Pontificia Universidad Católica del Perú
}

\section{Resumen:}

El presente artículo explora la conexión intertextual entre los ensayos y la exploración poética de Javier Sologuren con clásicos de la literatura japonesa desde su primer encuentro con la expresión artística japonesa, sus estudios y los poemarios en los que vuelca en mayor medida sus conocimientos. Entre estos se profundiza en la relación entre su poemario Folios de El enamorado y la muerte (1980) con la narrativa breve de Yasunari Kawabata, el recurso del haiku y de la fragmentariedad para entretejer percepciones y recuerdos así como la cercanía temática con las preocupaciones de la corriente contemporánea de la nueva sensibilidad japonesa.

\section{Abstract:}

This article explores the intertextual connection between essays and poetic exploration of Javier Sologuren and Japanese classics literature. From his first encounter with the Japanese artistic expression, he pours into his studies and collections of poems to the best of his knowledge. 
Which relationship deepening on between his Folios de El enamorado y la muerte (1980; Folios form the Lover and Death) and the brief narrative of Yasunari Kawabata; the usage of haiku and the fragmentary weaving perceptions and memories; as well as, the thematic proximity with the concerns of the contemporary trend of the new Japanese sensibility.

Palabras clave: Sologuren, Kawabata, literatura japonesa, intertextualidad, poesía.

Keywords: Sologuren, Kawabata, Japanese literature, intertextuality, poetry.

Recibido: 31/01/2016

Aceptado: 20/02/2016

Cuando hablamos de la literatura japonesa en el Perú, es inevitable mencionar a Javier Sologuren, un poeta de gran prestigio. Maestro, editor, traductor y ensayista; su obra revela la profunda influencia de esta tradición. Para él, el hombre se reconoce en su identidad humana a través de la cultura, y debido a su universalidad no debemos ser ajenos a distintas tradiciones.

Su encuentro con la cultura japonesa fue anecdótico y casual, como cuenta para Alonso Rabí do Carmo en el libro Animales literarios (2008). En la esquina próxima a su casa había una cafetería de japoneses y el joven Sologuren quedó maravillado pensando en el largo camino que habían recorrido hasta llegar al Perú. Un segundo encuentro fue en otra tienda, también de japoneses, que se encontraba cerrada, pero al 
pasar escuchó el sonido de un instrumento musical, era un shamisen y «de ahí a los libros, a la literatura japonesa, no hubo sino un paso» (Rabí do Carmo 2008: 135-136). En Poesía china y también en Noticias sobre Lao She comenta haber tenido su primer contacto con la literatura de Oriente a través de las novelas de Pearl S. Buck, entre estas, La buena tierra. Por esa serie de coincidencias, este escritor se abocó a esta literatura, viajó tres veces a Japón y hasta fue rehén en la residencia del embajador Aoki.

La Segunda Guerra Mundial trajo al escenario una cultura desconocida en Occidente, la japonesa. Los haikus y los tankas pasaron a ser reconocidos en Europa como un arte delicado y de buen gusto, comenzando a multiplicarse las traducciones y también los estudios antropológicos que hicieron que Javier Sologuren se acercara a ella.

Entre los primeros pasos de su trayectoria como estudioso de la literatura japonesa podríamos tomar la publicación de la traducción del drama Izutsu de Zeami Motokiyo y una traducción de Cinco amantes apasionadas de Ihara Saikaku, realizada en colaboración con Akira Sugiyama.

En Al andar del camino II (Sologuren 2005) tenemos otra lista de artículos relacionados con el Oriente: «El meridiano poético oriental», «Puerta abierta a China hoy y siempre», «Un cervantista japonés», «En el mundo de los proverbios chinos» y finalmente «Poesía japonesa de mediados del siglo veinte». En este último presenta poemas traducidos del inglés por Ilia Sologuren, que a su vez fueron traducidos por Naoshi Koriyama y Edward Lueders del japonés. Los escritores traducidos 
son Akiya Yutaka, Kusano Shinpei, Yoshioka Minoru, Shibusawa Takasuke e Irizawa Yasuo.

El rumor del origen fue un gran proyecto de traducción publicado en 1993. El título de esta antología de literatura japonesa nos recuerda el «origen», el momento en que el «ser» surge del «no-ser», pero, a la vez, evoca a El rumor de la montaña, un libro de Yasunari Kawabata. En la antología se encuentra un ensayo escrito por Javier Sologuren en conmemoración a los trescientos cincuenta años del nacimiento del poeta Matsuo Basho. Además cuenta con relatos de autores contemporáneos como Naoya Shiga, Jun'ichiro Tanizaki, Ryonusuke Akutagawa, Yasunari Kawabata y Yukio Mishima. Por último incluye también ensayos de autores nipones que nos acercan a una forma diferente de apreciar las obras literarias.

Su siguiente antología japonesa, elaborada en colaboración con su esposa Ilia, fue titulada Poemas y cuentos del Japón (1995) y publicada por el Centro Cultural Peruano Japonés. Para el año 2000 había publicado también una selección de teatro y cuentos japoneses llamada La luna en el agua.

Vale citar Hojas de herbolario, una compilación que nace a partir de apuntes sobre temas diversos de los años noventa. Tenemos algunas páginas (hojas) de este arbolario escritas sobre temas orientales como: Una belleza inmune a las mudanzas del gusto; Hokusai el calígrafo; La brevedad del haiku; Momotaro...; Sin pretender...; Despertamiento, en el que habla sobre Yasunari Kawabata; y El embalaje en el Japón..., de donde provienen observaciones sobre el arte y el diseño en el espacio. Estas observaciones son contrastables con la perspectiva espacial 
de su poesía. Luego, curiosamente, vienen una serie de anotaciones sobre la traducción en general, donde cita a diversos autores, entre ellos Alfonso Reyes y Borges. Sologuren intentaba extraer lo puramente humano a través de sus traducciones, reto enorme al encontrarse con lo oriental.

\section{Obra poética}

Javier Sologuren se consideraba parte de una tradición de poetas dedicados a la experimentación formal. Entre sus poemarios de mayor experimentación e influencia oriental se encuentran Folios de El enamorado y la muerte (1980) y Jaikus escritos en un amanecer de otoño (1981) 1.

En un breve espacio, Roberto Paoli en su libro Estudios sobre la literatura peruana contemporánea (1985) reflexiona sobre la prevalencia de la composición de tres versos cortos, parecida al haiku en nuestro autor, según un gusto que se remonta al mexicano José Juan Tablada, uno de los primeros poetas hispanoamericanos en valorar lo gráfico y espacial del poema. El japonesismo debería considerarse componente esencial del arte fino y burilado de Sologuren, de sus preocupaciones gráficas y espaciales, y debería, además contextualizarse en la vocación específica de la poesía hispanoamericana, para él, muy sensible a las civilizaciones de extremo oriente. Por ello es que en el uso de los espacios blancos y también de la omisión del espacio tipográfico para ciertos grupos de palabras, alineaciones

Nótese que Sologuren no conocía aún la escritura romaji, versión estandarizada de la escritura japonesa con el alfabeto romano. En esta «jaikus» vendría a ser «haikus». 
verticales y oblicuas, continuos, columnas, se relaciona con el arte de la escritura del Japón, como señala el autor en «Hokusai el calígrafo».

Si seguimos la línea cronológica, el primer poemario que posee la marca de Oriente sería La gruta de la sirena (1961), donde su estilo precedente se integra con formas nuevas, sea el poema en prosa, la composición al estilo de haiku y la experimentación espacial. El haiku, propiamente dicho, aparecerá por primera vez en Corola parva (1977) y se coronará con Jaikus escritos en un amanecer de otoño (1981). Para Ana María Gazzolo (1989), muchos de estos haikus no abandonan del todo el espíritu y las preocupaciones de un occidental, pero, en mi opinión, muestran la capacidad de síntesis de formas e intereses de un poeta frente al mundo.

Un ejemplo de esta capacidad de síntesis es Folios de El enamorado y la muerte, publicado en 1980, en la madurez de su obra poética. La selección en el espacio sugiere el sentido del poema, una lucha entre la palabra y el silencio que se ve traducida en una dicotomía entre la vida y la muerte. El simbolismo de los folios es la tragedia del cuerpo físico en su experiencia de enfrentarse a la muerte, es que el enamorado es equivalente a la poesía y a la vida humana, así como la Muerte es al silencio y al vacío que está más allá de la vida. Sologuren parece entender que lo que está fuera del lenguaje, lo está también fuera de la vida, inscrito en un mundo donde todo parece avanzar hacia la muerte. Comparte con Yasunari Kawabata la conciencia de la finitud y de no querer seguir adelante. Así encuentra 
que es en la continuidad de la escritura donde radica la vida, como un proceso, un movimiento o transcurso de lo real. Este poemario simboliza la victoria de Eros sobre Tánatos en la tierra, espacio existencial y medio de la memoria.

Otra de las revelaciones de este poemario es el descubrir a un Sologuren partidario de la estructuración, siendo la composición del poema su verdadero tema y reflexión sobre el mundo. También se hace presente la búsqueda de la plasticidad en la expresión, que lo hace recurrir a la imagen y disponer los versos con espacios blancos, que colaboren en la significación total del poema en tanto ritmos y sentidos. Esto se logra por medio de la ausencia de signos de puntuación convencionales, batallando contra el silencio para expresar lo preciso, utiliza signos gráficos alternativos o aglutinación de palabras.

El poema epitalamio plantea la trascendencia de la muerte a través de la memoria. En él los amantes entrevén que cuando hayan muerto, los amantes vivos llegarán a ellos y de este modo no solo se producirá el renacimiento simbólico de los muertos como raíces, sino también el deslumbramiento de amor de los vivos; nuevamente el tema de Eros sobre Tánatos en donde la noche es símbolo de la búsqueda de la otra realidad.

También tenemos los poemas «Dos o tres experiencias de vacío» $\mathrm{y}$ "A la sombra de las primicias de verano», donde la realidad es velada y no tenemos oportunidad de profundizar en los mecanismos que la manejan. Es por esto que a pesar del amor, la amistad, 
la solidaridad y el arte que ayudan en la búsqueda del yo poético, los resultados parecen vacíos. Se ha escrito solo y para la belleza, pero sin ningún cambio en la realidad espiritual. El tema de la escritura como algo que no cambia la realidad forma parte importante de este poemario.

Otro rasgo de este poemario es una visión positiva hacia la experimentación, Sologuren destaca entre la influencia de la poesía concreta, conceptual y japonesa, a esta última. Menciona que él escribe «a la manera de tankas y haikus», seducido por la brevedad, pero sobre todo por su capacidad de sugestión y la sutileza expresiva que estas formas alientan. Son rasgos que no solo adjudica a la poesía japonesa, sino también a los relatos de Yasunari Kawabata. En «Kawabata y las profundidades del espejo» Sologuren concluye: «está mirando, escrutando en las profundidades del espejo. En ellas habrá de encontrar que al cabo de toda la vida solo quedan dos certezas, dos heridas: el amor y la muerte. [1977]» (2005: 116, t. VII). Son precisamente estos, el amor y la muerte, los temas de Folios.

Es inevitable relacionar Folios de El enamorado y la muerte con Folios de mi decimosexto año, títulos del poemario y de los documentos que el joven Kawabata va escribiendo durante sus viajes antes de terminar sus estudios respectivamente. Además, uno de los poemas de Folios y que muchos consideran desvinculado con la temática del poemario, "Al resbalar el silencioso aceite del día», es una reinterpretación de Kawabata. El poema refiere al relato «Aceite» de Yasunari Kawabata, perteneciente a la parte primera del libro 
Izu no odoriko 伊豆の踊子 (La bailarina de Izu) (2006). En este relato, Kawabata reflexiona sobre su orfandad, los recuerdos y la manera en que se enfrentó a la pérdida de toda su familia a pesar de ser muy pequeño como para recordarla. Fundamenta su aversión por el aceite y las concesiones que sus abuelos hacían con él, con una historia contada por su tía, según la cual, el pequeño Yasunari habría roto la lámpara de aceite del altar budista en el funeral de su padre. Desde ese momento, aunque entre sus tres y catorce años fallecieron todos sus familiares directos, la familia de Yasunari reemplazó las lámparas por velas sin que el niño supiera la razón.

Esta reflexión sobre la existencia y el recuerdo que surge de «Aceite» y se refleja en $\mathrm{Al}$ resbalar el silencioso aceite del día se repite en «dos o tres experiencias de vacío» $\mathrm{y}$ «A la sombra de las primicias de verano» en el mismo poemario. Miguel Cabrera (1988) también encuentra esa visión totalizadora de la problemática existencial, ya que la realidad para Sologuren sería profundamente espiritual.

Al resbalar el silencioso aceite del día
(Imagen de mi madre)
mirando en un punto no lejano
del sol
ya consumido en sus cenizas áureas...

(Sologuren 2005: 268, t. I)

En mi lectura de este poema, la imagen de la madre es construida desde un ideal de decoro o elegancia, comparable a las inspiradoras geishas de La bailarina 
de Izu. Las cuatro primeras líneas podrían referir tanto a los cabellos de la madre convertidos de sol a gris, pero también a las cenizas (tema recurrente en Kawabata) que quedan del difunto. Queda el detalle de la luz que representa la madre, el sol, que analizaremos en breve.

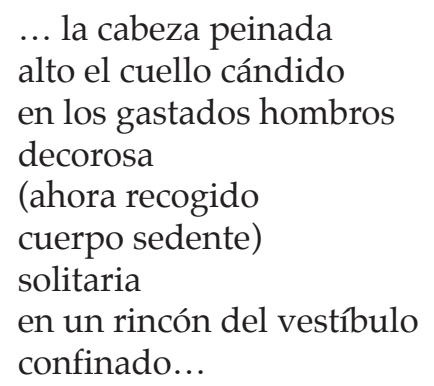

(Sologuren 2005: 268, t. I)

En los gastados hombros hay esfuerzo, pero también es una decorosa figura aristocrática, la elegancia de los hombros caídos que remarca la seda de los kimonos. Ese cuerpo que está ahora recogido y sedente sugiere la postración de la edad o la muerte para confirmarnos la imagen del cadáver con la siguiente línea: en un rincón del vestíbulo, como un velatorio.

\author{
... en el pecho \\ (desde donde tu edad \\ vio levantarse \\ y se oyó decir \\ a sí mismo las palabras) \\ el tenue rayo \\ de una fíbula \\ (que apenas pudo tolerar
}


el doméstico afán)

su gracia secular

in tenebris

(Sologuren 2005: 268, t. I)

Un bello detalle es la pieza léxica rebuscada del poema: fíbula. Confinado en el pecho estaba el tenue rayo de un broche que soportaba apenas el ajetreo de la vida doméstica, en un pecho que se vio y se escuchó a sí mismo envejecer. La gracia secular de mundo de la vida diaria queda en la oscuridad.

Si bien Kawabata perdió todas las fotos de sus padres, Sologuren sí conserva una imagen mental muy poderosa de su madre, a la cual alude en el poema. Al contrario del cuento, que termina citando al abuelo «¿La luz es más brillante ahora, no?», el poeta finaliza evocando la oscuridad, lo que sugiere que al contrario de Kawabata con la revelación del aceite, Sologuren se niega a aceptar su orfandad o la pérdida de los recuerdos, los cuales, a pesar de ser analizados no lo liberan.

Ambas obras nos remiten al cuestionamiento sobre el recuerdo y el olvido, pero sobre todo, nos remiten a la muerte. El poemario al que pertenece este poema cuenta con dos epítetos, «aquella blancura que habitaba las profundidades del espejo era la nieve», de Yasunari Kawabata, y la segunda «entonces, a mi humano corazón súbito vuelvo», de John Keats.

En la entrevista ya citada Sologuren confiesa:

Vivir es morir, y morir es vivir. Pienso que el gran mal en nosotros sea tal vez haber concebido la muerte como un tajo definitivo a un proceso, cuando este se da justamente 
por la participación de ambas realidades: vida, muerte. No sé, no quiero naturalmente pretender una filosofía profunda al respecto. Es algo que se me ha ido imponiendo. (Cabrera 1988: 68)

Con respecto a la temática de su poesía, en el extenso poema «Recinto» las imágenes de la muerte son las de inapelable y perecedera, que están relacionadas con la juventud, el amor y el tiempo; como lo hizo Kawabata. Con ello se vincula el amor como una experiencia estética sublime, pero sobre todo el paso del tiempo retratado en las estaciones y el tema de la naturaleza, cuestionamiento perpetuo sobre la validez del recuerdo y de la identidad basada en la historia. El tema de la muerte es el que va tejiendo los temas de la vida, las preguntas de índole poética, filosófica y metafísica, llegando a poemas que para Cabrera (1988: 68) son los totalizadores, los que concentran la visión del mundo de Sologuren. La muerte para Sologuren no es aquel fin natural del hombre, sino también la tragedia del mundo actual en la que el hombre es lobo del hombre y a pesar de eso el autor confiesa que no pretende una filosofía profunda al respecto.

La ya mencionada indagación en el sentido existencial y metafísico del recuerdo y una realidad espiritual que realiza en Folios, parte de la visión del autor sobre estas ideas como comunes a la esencia humana a pesar de nuestras distancias culturales y geográficas. Así, se relaciona con Kawabata y Mishima en la búsqueda de un equilibrio entre la carga poética y la forma que debe conducirla. Sologuren dice: 
Hay algo en la obra poética, en la obra artística y, en general, en la cultura, que está vivo a pesar de las fronteras tanto temporales como físicas, que le hace posible el acceso al hombre, y no solamente eso, sino que el hombre se reconozca ser tal, con su identidad humana en este gran banquete, en esta gran celebración que es la cultura. (Cabrera 1988: 39)

Pueden haber oscuros designios de la realidad, como la muerte de la madre, pero en poemas como «A la sombra» toda la investigación sobre este tipo de preguntas metafísicas es en vano. Como única solución se queda con los libros y la memoria, nociones ya cuestionadas en «Al resbalar...» para combatir la oscuridad. Sin embargo, la solución está en apelar a aquello que es lo más tangible de lo que se posee: el cuerpo, que es vida y muerte a la vez.

Considero pertinente aludir también a 母 (haha) Madre, escrito en 1926, relato vigésimo octavo de los 掌の小説 (Tenohira no Shosetsu) Relatos que caben en la palma de la mano, en 1972, (Kawabata 2011), en el que se reflexiona sobre la femineidad asociada a la figura de la madre como predecesora de la amada, comenzando con unos versos:

Esta noche estuve con una mujer.

$\mathrm{Al}$ abrazarla... la suavidad femenina.

Mi madre también era una mujer.

Derramé lágrimas, le dije a mi nueva novia:

Sé una buena madre,

Sé una buena madre, pues yo no pude conocer a la mía. 
Con respecto a la idealización de la mujer por Kawabata, Lawson (s.f.) nos describe ciertos elementos, el amante como protagonista, la mujer idealizada como el objeto de su amor, el amor no correspondido y el desplazamiento de los valores espirituales asociados con el amor para ser recogido en una tranquilidad estética. Es un modelo simple pero completo.

El de Sologuren es un retrato femenino muy parecido a las inspiradoras geishas de Kawabata, en las que busca la femineidad perdida del rostro materno. Desde el punto de vista del psicoanálisis, el hijo inconscientemente busca a la madre en cada mujer que se le presenta, para Jung el arquetipo de la madre es de vital importancia junto al arquetipo del ánima. Siendo las proyecciones de la madre desencadenantes de atracción o repulsión erótica basadas en la identificación o su ausencia.

La ausencia de la madre intensifica el anhelo de encontrar su figura en otro ser, pero también la melancolía al notar que no es posible. En el caso del escritor japonés, la imagen de la madre es una colección de imágenes mentales de su niñez que se quedaron grabadas en su memoria al esforzarse en recordar un rostro que desapareció antes de que él pudiera conservarlo como un recuerdo. Diferente es el proceso de Sologuren, quien recuerda fijamente la expresión de la madre fuerte, construida como un baluarte del equilibrio doméstico y el sacrificio. La imagen de la madre como heroína cotidiana se identifica con el arquetipo de la gran madre, la cual provee y es sinónimo de tranquilidad para el individuo. 
Una madre de este tipo, completa y humana, no es reemplazable ni comparable con otra mujer $y$, por tanto, su femineidad queda atada a un ideal. Entonces, a pesar de su aparente falta de correlación con la temática abordada, la idealización femenina esclarece y justifica la aparición de este poema entre los Folios de El enamorado y la muerte. De esta forma, el poeta se une a una sensibilidad universal de la femineidad, más allá de concepciones culturales, llegando a la imagen primera y arquetípica de la mujer, la de la madre.

\section{Jaikus escritos en un amanecer de otoño}

Para finalizar, no podemos ignorar otro poemario con gran influencia oriental. Javier Sologuren no se consideraba un escritor de haikus propiamente dichos, al no ser japonés ni hablar el idioma ni estar inmerso en la cultura de la que estos son producto. Así es como para el autor su obra Jaikus escritos en un amanecer de otoño, escrita en 1981, pero publicada en 1986, son escritos «a la manera de» haikus. Sologuren se vio atraído por dos formas, el tanka y el haiku. De estos le interesaban la brevedad, la capacidad de sugestión y la sutileza expresiva. El haiku es una combinación de diecisiete sílabas en tres versos (repartidos en 5, 7 y 5) y el tanka de treinta y un sílabas en cinco versos. Ambos evocan la naturaleza e intentan extraer una cierta mística de la observación minuciosa de lo más simple. Parte de la magia de estas formas poéticas japonesas es la sacralización de lo cotidiano, como podría decirse de la ceremonia del té o de la meditación. Es el ámbito de la renovación de ciclos naturales, el sueño, el amor, la escritura, los recuerdos y 
el dolor. La poesía para Sologuren es sinónimo de vida, es la expresión de esta y ahí donde hay vida también hay horror por la muerte, el mundo contemporáneo y el futuro.

Estos son solo breves ejemplos de nexos y referencias que pueden encontrarse en la obra de Javier Sologuren, un artista peruano con una sensibilidad abierta hacia Oriente. Sienta entonces un precedente entre los estudios interculturales y la voluntad de difusión de una literatura que parecía muy lejana y que cada vez se encuentra más cercana a nosotros. 


\section{Bibliografía}

CABRERA, Miguel Angel. Milenaria luz: la poesía de Javier Sologuren. Barcelona, Ediciones del Tapir, 1988.

GAZZOLO, Ana María. «Javier Sologuren: poesía, razón de vida», en Lienzo. № 9. Lima, 1989, págs. 219-278.

KAWABATA, Yasunari. La bailarina de Izu. Trad. de María Martoccia. Buenos Aires, Emecé Editores, 2006.

. Historia de la palma de la mano. Trad. de Amalia Sato. Barcelona, Austral, 2011.

LAWSON, R. N. «Kawabata's Unrequited Lovers». (s. f.). http: / / www.washburn.edu/reference/bridge24/Kawabata.html (revisión 6 de febrero, 2015).

PAOLI, Roberto. Estudios sobre literatura peruana contemporánea. Firenze, Stamperia Editoriale Parenti, 1985.

RABÍ DO CARMO, Alonso. Animales literarios: [17 entrevistas]. Lima, Aguilar, 2008.

SOLOGUREN, Javier. Obras completas. Lima, Pontificia Universidad Católica del Perú, Ediciones del Rectorado, 2005. 